\title{
COLOMBIA DESDE LEJOS
}

G

vando se torna distancia de las parsonas, las cosas, las instituciones... ellas Antora aparecen en nueva perspectiva, a veces embellecidas por el afecto $y$ la ilusión, magrificadas en lostastancialy desdibujadas en sua aristas del diario discurrir. El hogar desde lejos se vuelve más dulke hogar, la patria a distancia se nos antoja menos madrastra y més madre.

Despux́s de 24 meses inolvidables e intensos, pasados en Manizales, en los que viví los dos últimos años de la administración Gaviria, participé en el apretado afio electoral del 94 y tuve tiempo de consultar fuentes vivas $y$ escritas, y oportunidad de analizar realidades actuales colomblanas, me ha parecido oportuno colaborar con estas líneas desde Venezuela, para la revista ANFORA qua me tuvo como iniciador en 1993.

El tema me bo ha sugerido la visita oficial de dos días que el 11 y 12 de Octubre de 1994, hieo el presidente Ernesto Semper a Caracas, acompañado por cinco de sus ministros (Defensa, Relaciones Exteriones, Desarrollo, Comercio Exterior, Justicla) y un representativa grupo del empresariado colombiano. Fú unánime el camentario de la prensa (no siempre bien dispuesta para Colombia) elogiando el discurso de Samper ante el parlamento venezolano, sin papel ni telepronter, en estilo directo, franco, pragenático, sin tocar resquemores del pasado e invitando a una empresa común hacla el futuro. Y periodistas-políticos avezados, como dosé Vicente Rangel, destacaron el fuerte contraste que se observa actualmente entre Colombla, que avanza indetenible hacla adelante, bajo un bderazgo joven, dinámico y moderno, que vierse encarnado en toda una generación empresarial y politica de relevo, y la actual Venezuele, con un granestadista al frente de sus destinos pero ya envejecido, una cluse polltica cansada, un

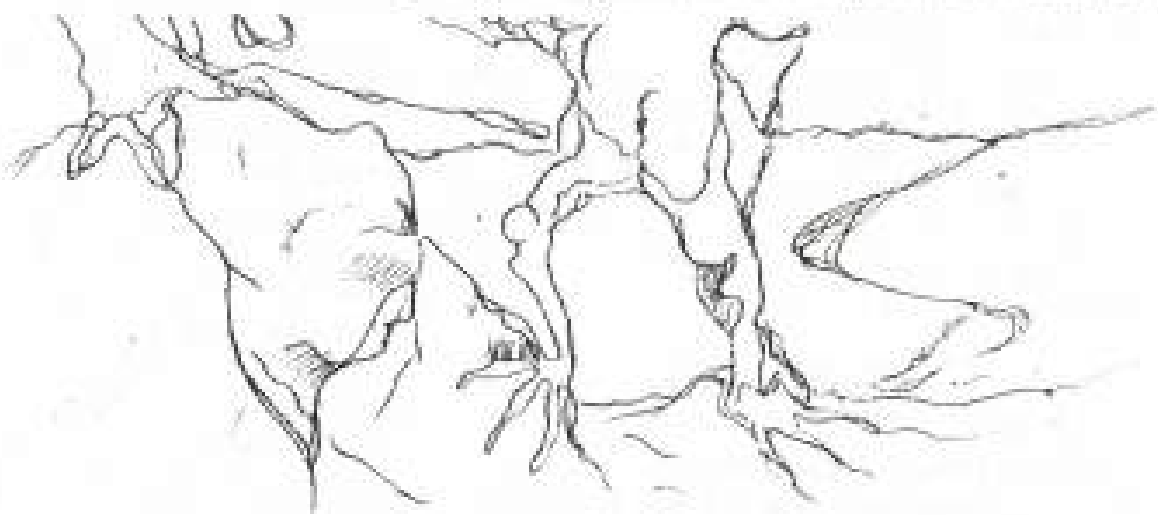

Uhinersidad Autchoma 35 
empresariado atado a los privilagios del pasado, y problemas acumulados que requieren para su solución más imaginación y dinamismo.

\section{DE LA BARBAPIE A LA IMAGIHIACOOH}

En 1989, cuando el cartel de Medellín quiso poner el pais a sus rodillas con bombas y narcoterrorismo, el panarama de Colombia era sombrio y catastrófico, similar al contemplado por Jeremias en sus Lamentaciones sobre la cludad amurallada de derusalem, prúxima al colapso. La barbarie parecía haberse adueñado, otra wer, de ese pueblo sufrido y trabajador, que tantas crisis ha sobrellevado. Pero como el Ave Fénix, con una imaginación y una voluntad increible de superviviencia, este pais de eontrastes y paradojas, prosiguió su destino histórico con nuevo aliento. Ha sabido renovar sus institucionesy su práctica politica. Supo encontrar el relevo jowen para sustifuir a Luis Carics Galán, quien era la reserva para el futuro y habia caido asesinado -en aciaga hora- por las balas de los sicarios del narcotráfica. Colombia supo llevar con equilibrio el arriesgado proceso de darse una nueva Constitución Politica. De entonces aca, ha depositedo su voto en nueve comisios generales para darse dos nuevos Presidentes jóvenes (Gaviria y Samper), elegir a los 90 miembros de la Asamblea Nacional Constituyente, elegir por dos veces 1.017 Abaldes de municipics y 32 Gobernodores de departamentos y renovar en dos ocasiones gran parte de la clase politica del Congreso. Superó la ola crítica del narco-terrorismo al desmantelar el cartel del Medellín y liquidar a sucapo, Pablo Escobar, en diciembre de 1993. Con brazo fuerte y diálogo político va tratando de asfixiar las guerrillas superstités, Y prosigue adelante en su desarrollo, abriendo al exterior su economía y sus fronteras. La realidad de este extrańo y paradógico país que es COLOMBLA, va superando la misma imaginación.

\section{VISION IMPACTASTE}

De ese pais, -tan maltratado por los medios de comunicación propios y ajencs- he regresa-

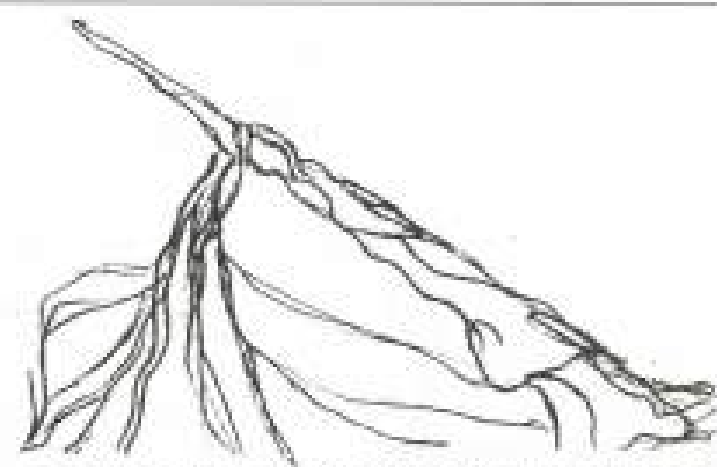

do a Venezuela profundamente impresionado e impactado. Por todas partes - por el campo y las ciudades- $y$ a todos los niveles -nivel popular, de clase media, y de alta dirigencia empresarial, cultural, eclesiástica, politica-se percibe un dinamismo modernizante, una productividad sin reposo, una férrea voluntad de mejorar y una aplicación colectiva al progreso, que por muchas que sęan las dificultedes y limitantes de tipo coyuntural, llevan a perisar que un pais así tiene inevitablemente asegurado tin buen futuro y no a muy largo plazo.

Hay una realidad irrebatible contra la cual se estrellan nuestros propics prejuicios, las medias verdades de los medios de comunicacióny el escepticismo quejumbroso de los mismos colombianos. En los últimos 35 años -como lo reconoce el último estudio del Sela-Colombia es el pais dentro del Tercer Mundo que con más constancla y tosudez viene descontando ventaja al sub-desanollo, Y hoy se ubica encabezando un pelotón de naciones intermedias -con suficiente infraestructura sccio-económica y aliento progresista-como para ser -en otros 35 años- un país dearrollado, con el nivel de Esperna dentro de la actual Unión Europea.

Recientes análisis de especialistas serios, tanto nacionales como extranjeros, relievan con base en datos estadisticos, esta curva constante de crecimiento y desarrollo integral, que algunos llaman "el milagro cobmbiano", como se habló años atrás de un "milagro ale. mán' y de un "milegro japonés". Es exagerado llamarlo así. En Colombia más que milagro, lo que ha habido es sensatez y continuidad, a través de 10 administraciones que no hipoteca-

\section{Rinstankon}




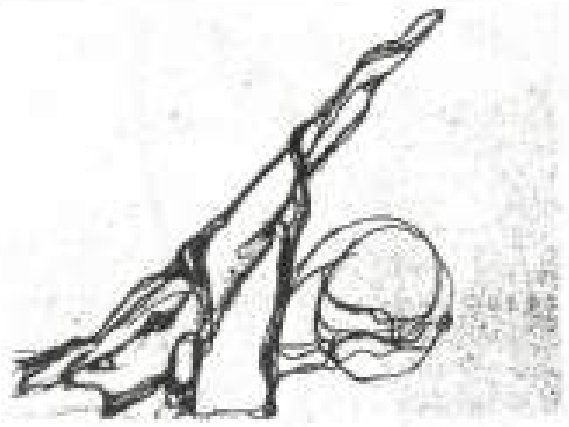

ron el pais, que no despilfarraron los limitados recursos del Estado y planearon un desarrollo constante sin caer en los excesos del desarrollismo, del monetarismo y del populismo que han hecho tanto estrago en casi todos los paises de América Latina. Esta ponderación estatal y esta sensatez ininterumpida durante 35 años es, de por sí, un milagro en nuestras batitudes tropicales de Asia, Árica, América Latina. Pero para los analistas, el verdadero milagro colombiano sí puede ocurrir en los próximo años.

Las proyecciones paracomienzos de siglo señalan que para entonces Colombia puede haber llenado todos los requisitos pora iniciar el gran "salto hacia adelante" y el verdadero "despegue" hacia el desarrollo (1).

\section{LAOTRA COLOMBLA}

La verdadera Colombia no es la del narco-terrorismo en el 89 y el asesinato del futbolista Andrés Escobar en 194 , consus masacres y crimenes pagados a sueldo. No es la de la guerrilla obcecada con sus voladura de oleoductos $y$ secuestros a ganaderos. No es la de esas minorias apátridas, que vienen arrojando tinta roja sobre el mapa verde y multicolor de Colombla.

La verdadera Colombia es una mayoría sileciosa de 36 millones (2) que trabaja, crea riquera, asimila tecnologias, se prepara edu- cándose b mejor posible, se apesiona por al toreo, el fútbol y el ciclismo, y sabe también divertirse. (3) Es una Colombia curtida por el sol, fuerte en su duro bregar, dueria de una soberania que se expresa en sunueva Constitución Politica y en ininterrumpidas elecciones. Es una Colombia que actía incansablemente por debajo de esa capa sensacionalista de noticias que cada dia repiten el mismo ritornello de "un pais al borde de la disolución", parquse no conocen otro. Colombia es esa paradoja resultante de un desarrollo sostenido y una violencia casi endémica. Es un pais atípico en América Latina de violencia y perticipación politica; de droga, guemilla y extraordinario desarrollo económico, que no cabe en los "modelos" de análisis que suelen aplicarse a los demás paises.

En forma imparcial ha expresado esta realidad -para muchos desconcertante- la revista madrileña UNO en un artículo que mantiene actualidad y cuyo titulo resulta diciente: "E Ave Fénix de América" (4). Algunas de sus. apreciaciones:

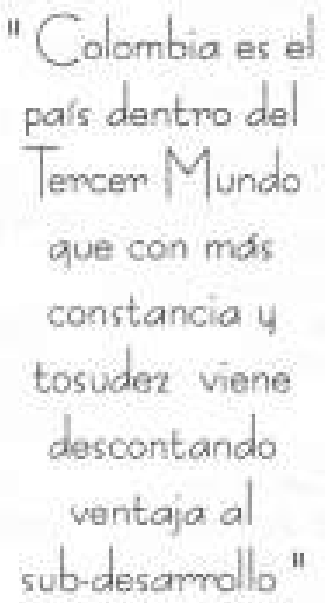

QQuien examine las meras estadisticas supondrá que Colombia es un pais al borde de la disolución. Todo lo contrario. Es uno de los más prósperos y con mayor futuro en América Latina (...) Qué pasa, por ejemplo, con la democracia colombiana? Es una de las más sólidas y antiguas delcontinente (...) El Elingreso per capita se mantiene estable en unos US\$1.500, $y$ el Producto Interno Bruto sigue aumentandoa un ritmode 4 a $5 \%$ anual $(. .$. Aunque parezca une paradoja, la combinación entre la prosperidad económica y las administracioneseficaces han tomado indiferentes a los colombianos ante las casi cotidianas explosiones de violencia (...) Una de las ventajas de Colombia es la distribución homegénea de sus habitantes. A diferencia de los otros países de América Latina, en la capital sólo vive el 15\% 


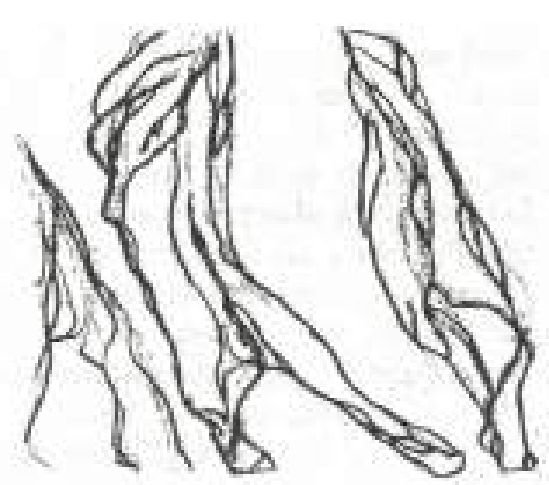

de la población total; otro $15 \%$ se distribuye en las otras cuatro ciudades mayores: Medellin, Cali, Barranquilla y Cartagena. En pocos paises como en Colombla la sensatez y la voluntad de servicio rigen la conducta de la clase politica. Hay una continuldad administrativa tan marcada, que hasta los apellidos de los presidentes se repiten, y eso les impone una severa responsabilidad histórica. Todos los an̂os, la guerrilla o la droga ponen al país a crillas del abismo. Y todos los años también Colombia renace, cada ver con más energia".

La otra Colombia es el pais joven. Leno de recursos, de gente trabajadora y entusiasta, que mira su futuro con optimismo y genera siempre nuevos campos de acción. Esta es la verdadera Colombia. La que conatruye cada dia un porvenir más claro y mejor. Y no se trata de una ficción ni de un piadoso deseo para el futuro. Es una realidad que se mueve a pesar de las actuales ataduras limitantes. $Y$ que avanza a pesar del pesado lastre y la continua defensa que el "fuego cruado", por todos sus flancos, le impone.

A contra-comiente de un generalizado escepticismo de propios y extraños, yo sigo almentando suficientes elementos de juicio como para poder afirmar que el futuro de Colombia no es negro, sino promisorio. Colombia es muchas cosas hoy, pero ciertamente no es el Apocalipsis. Colombia es un pais que ha demostrado con hechos - por más de 90 años-que sabe salir adelante de las situaciones más negativas y conflictivas, situaciones que para otros pueblos serian sencillamente apabullantes. Los

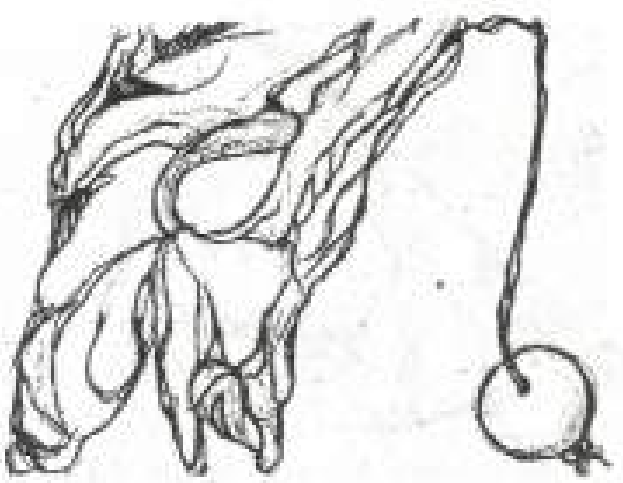

tropiezcs de ahora no son superiores a los que ha superado años atrós. Colombia tiene una vitalidad tropical de selva tupida y una salud de Eana trepadora, que ahogarb́ saludablemente los peores pronósticces. De los males sabe sacar bienes $y$ de los bienes un futuro mejor. M posición podrá parecer a muchos demasiado optimista e ilusa. No lo discuto. Pero la prefiero a una posición demotista y pesimista, que en vez de empujar hacia adelante, peraliza energias, desautoriza esfuerzos de las generaciones de relevo, veta nuevas empresas. Sigo haciendo mía aquella frase de Albert Schwetzer, gran téblogo luterano y misionero médico en poblados africanos "mi visión es trágicamente pesimista, pero mi corazón es siempre optmista!".

*PhD, Aobislibya, ex-dibector del Departamento de Ciencias Hurnanas de in Chiversidad A uldinoms de Maneivales, Aundador y anterior divector de ba mensita ANFORA. Actualnente en in Chinersidad de los Andos. Merrida - Venesuela.

(1) Es cowwriemle a este reapecto el interesante estudio del especialata en desarvollo social, Enrique Peñaloes Camargo, titulado "La lartalecea de la democancin en Colombla" publicado en lo revista internacional Ciencia Poitica, Bogets No, 12 (ps) 77-84).

(2) 35.886-260 personas dib el Censo de Pobiación y Viviench realiado en ectubre de 1993.

(3) -Somos infurtivos, autodidactas, espontáneos y thipidos, y trabajadores encarniados, pero nos enibquece la sola idea del dinero tícil" IGarcia Márquez, Introducción al informe de la Misión de Ciencia, Educación y Desamollo, 22 julo1994).

(4) Revista "Uno", Madrid, No. 12, septiembre 1989, p. $24-25$.

\section{Rivitarion}

